by Major H. G. Prout of the Egyptian Staff are also of value, and are accompanied by a map of routes in the two provinces, constructed by the Society's dranghtsman from the reconnaissances of various officers in the service of the Khedive. Mr. E. Colborne Baber, lately our Consular representative at Chungking in Western China, also communicates through the Foreign Office some brief remarks under the heading of "Approximate Determination of Positions in South-Western China," to which are appended a number of tables of observations for latitude, \&c.

IN the middle of last January Mr. W. S. Jerdan and a small party started from the Elderslie station on the Diamantina River, in Western Queensland, for the purpose of exploring the Mackinlay Ranges for gold. Leaving the Booker-Booker Mountain, with its dark fringe of gidya scrub, on their left, and Mount Munro on the right, they travelled up the Diamantina over splendidly grassed downs, and as they advanced up the river they found that the grasses became even finer and herbs more plentiful. After eight days' marching the party reached the neighbourhood of the Mackinlay River, and they report that the country passed over for some time previously was principally level plain, and just at that season perfectly bare, with the exception of a few tussocks. After about another week they got out of the low country and obtained their first good view of the Mackinlay Ranges, which they describe as presenting a very picturesque appearance in the distance, with their numerous pinnacles, peaks, and flat-topped mountains. The country along the ranges is covered with granite boulders, or else consists of decomposed granite flats infested with spinifex, with numerous sandy creeks running through it in all directions. The party spent about two months in searching for gold, but met with little success.

Signor BIANCHI has reported to the Milan Society, which sent him out to Shoa and other parts of North-Eastern Africa for the purpose of making commercial explorations, that he has been able to make some corrections in the position of places as given in our existing maps. Antotto he places in $8^{\circ} 53^{\prime} \mathrm{N}$. lat., $36^{\circ} 15^{\prime} \mathrm{E}$. long., instead of its present position further north. Fanfinni is really north-north-east and not south of Antotto, while the Salala Mountains are fifty kilometres from Fanfinni, and not close to it. Lake Zouay he has not met with, though his route ought to have taken him to it, according to the map.

The United States Navy Department have received through the Russian Government a letter from the Captain of the Arctic Exploration steamer Feannette, dated from Cape Serdze Kamen, August 29, 1879, which reports the arrival of the Feannette at that place on the afternoon of the above date. The letter states that the members of the expedition were all well, and that they expected to sail that night for Wrangell Land, by way of Kaliutchin Bay. This news has taken more than a year to reach America. The Corzein has arrived at San Francisco, and is reported to have searched all the region between Point Barrow and Herald Island, without finding any trace of the expedition. Still he thinks there is no reason yet to give up hope.

The new number of L'Exploration is an improvement on previous ones. We have a good article on the commercial relations between France and Russia; information as to the progress to their destination of MM. Revoil and Crevaux; an interesting analysis of an article on Ausland, on the country of Muata Yanvo, a letter from Dr. Quintin on a former expedition to the Upper Niger, and letters from Matteucci on the progress of his expedition in the Sudan. The notes are also much better edited.

CAPELLO and Ivens have furnished to the Portuguese Government a detailed account of their African explorations, a great number of drawings, and a comprehensive map containing an important part of Portuguese Africa, and also the adjacent territories. Next year Capello and Ivens will return to Africa to finish their explorations, and make a complete chart of the province of Angola.

THE death has just taken place at Pitminster, near Taunton, of Capt. Hobson, of the Royal Navy, who in his earlier days took an active part in the search for the remains of the late Sir John Franklin, and was the discoverer of the records which afforded the clue to the lamented explorer's fate. He was second in command, then holding the position of lieutenant to Capt. McClintock, who, in the year 1845, sailed in the Fox to search for the Franklin Expedition. Hobson was the leader of one of the parties which went in search of traces of Franklin, and he succeeded in finding the brief record which only too clearly set at rest the conjectures which the public entertained as to Sir John Franklin's fate.

THE expedition which left France on October 5 for the exploration of the country between the Upper Senegal and the Niger, though mainly for military and commercial purposes, is likely, if successful, to add greatly to the fulness and precision of our knowledge of that region of Africa. Astronomical, geodetical, and topographical officers accompany the expedition, so that we may expect important scientific results. The terminus on the Niger will be either Bamakou or Dina, above Yanina and Segon.

Col. Flat'rers has returned from his explorations in the Touareg region.

THE Wellington correspondent of the Colonies and Indio states that the area of the Crown forest lands in New Zealand in 1879 was estimated at $10,158,870$ acres, but it has been proved that some of the most valuable kinds of timber have been recklessly used, and it is said that at the present rate of consumption all the splendid kauri forests will be exhausted in twenty-one years, and that the value of the timber will be about $x \mathrm{I}, 000,000 \%$. He does not however appear to have taken into consideration the very serious effect which this wholesale destruction of forests will have upon the climate of New Zealand.

\section{PROF. ASAPH HALL ON THE PROGRESS OF ASTRONOMY $Y^{1}$}

A STRONOMY, in some of its forms, reaches back to the most distant historical epochs, and the changes that it has undergone during this long lapse of time give to this science a peculiar interest. In no other branch of human knowledge have we such a long and continuous history of the search after truth, of the painful struggle through which men have passed in freeing themselves from theories approved by the wise of their own times, and in overthrowing beliefs which had become incorporated into the life and culture of those times. Perhaps the grand array of the heavens, and the vast phenomena which they display, naturally led men to the invention of complicated theories; but these passed away at last before the test of observation and the criticism of sceptical men; and the Copernican theory of our solar system, Kepler's laws of elliptical motion, and the Newtonian law of gravitation, gave to astronomy a real scientific character.

The discovery of the laws that govern the motions of the heavenly bodies, and the construction of the theory of these motions, demanded from practical astronomy better observations and a more accurate determination of the orbits of the planets and the moon, or of the constants that enter into the problems of celestial mechanics; and this demand led to an improvement in the instruments, and in the art of observing. The astronomers and instrument-makers of England and France led the way in these improvements. The great national observatories of those countries were established, and in England, Flamsteed and Sharp, Bird and Bradley, were foremost in raising practical astronomy to the condition of satisfying the demands of theory. But theoretical astronomy was soon to receive a wonderful advancement. Perhaps no one contributed more powerfully to this progress than Lagrange. The writings of this man are models of simplicity and elegance; and yet so complete and general are his investigations, that they contain the fundamental theorems of celestial mechanics. By the invention and cerfection of the method of the variation of the arbitrary constants of a problem, and by the establishment of the differential equations of a planetary orbit depending on the partial differential coefficients of a single function, Lagrange reduced the question of perturbations to its simplest form, and gave the means of deducing easily the most interesting conclusions on the past and future condition of our solar system. To supplement this great theorist there was needed another lind of genius. Combining the highest mathematical skill with unequalled sagacity and common sense in its application, Laplace gathered up and presented in a complete and practical form the whole theory of celestial mechanics. Besides his numerous and brilliant discoveries in theoretical astronomy, Laplace gave us some of the finest chapters ever written on the theory of attraction, ${ }^{2}$ and a complete treatise on the calculus of probability.

I Address as Vice-President of Section A, at the Boston meeting of the American Association

2 "Ein schönes Document der feinsten analytischen Kunst."-Gauss. 
By such labours as these the questions of astronomy were brought into order and classified, and the attention of astronomers was directed better than ever before to the determination of the quantities which must be found from observation. Moreover, the refinement of analysis and the completion of theory brought out new and more delicate questions, not less interesting, and requiring more complete investigation and more powerful instruments. The careful examination and study of the instruments and methods of observation became necessary, as well as complete and rigorous methods of reduction; and finally there was needed a critical and satisfactory method for the discussion of observations. For these last improvements in astronomy we are indebted chiefly to the astronomers and mechanics of Germany.

Among those who contributed by means of their optical and mechanical skill to furnish astronomy with the instruments necessary for its further advancement, no one holds a more honourable place than Joseph Frauenhofer. This man began his scientific work at the age of twenty-two, and died at thirty-nine, and yet in those seyenteen years he gave to astronomy great improvements in the manufacture of optical glass, driving clucks for equatorials, and telescopes and micrometers, that in the hand of Bessel and Struve gave to observations a degree of accuracy hardly thought of before. To such men as Frauenhofer and his co-workers, who have carried on and improved the construction of instruments of precision, practical astronomy owes much; and yet, after all, the principal thing in a science is the man him self. No matter how excellent the instruments may be, the question whether they shall be used for the advancement of the science, and shall contribute the full value of their peculiarities to help towards increasing the accuracy of astronomical deter. minations, depends wholly on the astronomer. Again, astronomy is now so completely a science, and all its operations are so closely connected with theory, that no one is fit to have charge of an extended series of astronomical observations who has not a fair amount of theoretical knowledge. Without such knowledge his labour is apt to be thrown away, and is never so effective.

As a good example of what the modern astronomer should aim to be, we may take Bessel. To this man we owe a large part of our best methods for the examination and determination of the errors of our instruments and the introduction of complete and rigorous methods for the reduction of observations. Bessel's reduction and discussion of Bradley's observations was a masterpiece of its kind, bringing out the value of Bradley's work, which had lain unnoticed for more than half a century, and forming a starting-point for sidereal astronomy. This work was continued and perfected in his tables for the reduction of astronomical observations, published twelve years afterwards, a work that has done more than anything else to introduce order and system into practical astronomy. In the discussion of instruments and the determination of their errors, Bessel's conception of an instrument was that of a geometrical figure, and the positions of the lines and divisions of this instrument were considered with corresponding rigour. Although devoted almost entirely to astronomy, yet Bessel was an able mathematician, and of this he has left abundant proof. It seems to be necessary that a man should die and be forgotten personally before his work can be fairly estimated; but time adjusts these matters at last, and I know of no astronomer whose work promises to endure the judgment of the future better than that of F. W. Bessel.

It has been said that for producing the most puzzling compound of metaphysics and mathematics something which has neither height nor depth, nor length nor breadth, and which no one can understand, the German mathematician is unequalled. And at the same time it must ke said that, for clearness of conception and beauty and precision of expression, Germany has produced in Gauss a mathematician who is unsurpassed, and who is worthy a place by the side of Lagrange. Omitting all reference to the works of Gauss in theoretical astronomy and in geodesy, which are many and important, I refer here only to his method for the discussion of observations and of deducing the most probable values of our constants. Almost the entire work of astronomy is a vast system of numerical approximation, in which the first steps are obvious and easy, but where the theory soon becomes complicated and the labour enormous. Thus the calculation of the approximate orbit of a planet or of a comet is the work of only a few hours ; but the computation of the perturbations and the correction of the elements from all the observations may be the work of months and years. It is therefore of the highest importance that we should have a method for the diseus. sion of observations that will give us the best result, and which will introduce order and system into this department of astronomy. Such a method is that of least squares. For the complete theory of this method and for nearly all the arrangements and algorithms necessary for its practical application, we are indebted to Gauss. The invention and application of this method to the discussion of observations of all kinds seems to me one of the greatest improvements of modern times, and its proper use will lead to a steady progress in astronomy. We must remember, however, that this method does not undertake the improvement of the observations themselves, as some have seemed to think but, when rightly used, it produces simply the best result we can hope for from a given series of observations. It does not therefore dispense with skill and judgment on the part of the astronomer, but one is tempted to say that, if he has not these prime qualities, then the next best thing for him to have is the method of least squares. The use of this method has become one of the chief characteristics of modern astronomy, and if we compare the results of its application with those of the older methods, we shall see its superiority. Thus, for example, no astronomer of to.day who is accustomed to the modern methods of discussion, would be satisfied with the manner in which Bouvard represents in his tables the observations of Jupiter and Saturn, but would suspect at once some error in his theory of the motions of these planets.

The present condition of sstronomy is the result of the continued labours of our predecessors for many generations; and to this result the lapse of time itself has largely contributed. For the full development of the secular changes of our solar system, for an accurate knowledge of the proper motions of the stars of our sidereal universe, and of the great changes of light and heat that are going on among them, the astronomer must wait until future ages. It is his present duty to prepare for that future by making the observations and investigations of his own day in the best manner possible; and to do this needs a careful consideration of the present condition of the science. Although the objects for observation have become so numerous, and the range of investigation so wide, that there is room for the most varied talent and skill, yet there is danger that there may be a waste of labour either in duplicating work, or in doing it in an improper manner. Especially may this happen in observations of the principal planets of our system, and of the fixed stars. In the case of the planets the observations are abundant, and the orbits are already well determined, except that of Neptune, for which, on account of its slow motion, we must of necessity wait for time to develop its small peculiarities, if such there be. For all these planets the observations at one or two observatories are amply sufficient, and even then the observations ought to be confined to a short time near the opposition, or at quadrature, and so made that they may be easily combined into a single normal position, which will suffice for the theoretical astronomer. To scatter such observations over a period of several months is to throw away one's labour, and to leave to the computer the disagreeable duty of rejecting a part of the observations as useless. It seems to me, therefore, unwise for several observatories to continue heaping up observations of the four outer planets of our system, when ten observations a year of each planet will give all the data that are needed. Again, for all the principal planets, observation is now in advance of theory, except, perhaps, in the case of one or two of them. Thus, for Saturn, all the tables are decidedly in error, and, although an attempt has been made to accuse the observations of this planct, it is quite certain that the trouble lies in the theory; for in the case of Jupiter and Saturn we have the most complicated planetary theory of our system, and one that has not yet been completely developed. It seems to me, also, that observations of our moon might well be confined to one or two observatories. Here again observation is far in advance of theory, if indeed there be now in use anywhere a pure lunar theory. All the lunar ephemerides that we have are affected with empirical terms, and the lunar theory itself remains an unsolved mystery. In this case there is no attempt to impeach the observations. The trouble seems to be with the perturbations of long period, and this does not call for numerous observations during each lunation. By a proper consideration of these matters astronomers may, I think, save themselves much useless labour.

Observations of the fixed stars are of the utmost importance in astronomy, since the positions of the stars are of the fundamental points on which depends our knowledge of the motions of the planets, the moon, and of the stars themselves; and it is 
on account of this fact that Bessel's tables, published in 1830 , were of such great service, since they introduced correct and elegant methods of reduction, and clearly defined all the constants and epochs. We now have the positions of several hundred stars so well known that they may be safely used in the reduction of observations; and for these accurate positions we are largely indebted to the astronomers of the Pulkowa Observatory, who have made such absolute determinations a special work. There is still an opportunity for the improvement of these positions, and every well-executed determination will be of value; but it is doubtful if crude and irregular observations can add anything to our knowledge of the positions of these stars. Neither can the routine, mechanical style of observing, that is apt to prevail in large observatories, be of much use here. It would be better in most cases for such observatories to assume the positions of the fundamental stars, and to leave the further improvement of their places to skilful astronomers who understand the theory of such work, and who carefully study and become masters of their instruments. In these refined observations the refraction of light by our atmosphere also plays an important part, and this question will need to be examined at every observatory that undertakes to do independent work. It is true that every new and good meridian instrument may, and perhaps ought, to contribute something towards removing constant errors, and giving us a more accurate knowledge of a star's position; but when this position is very well known, the only way for further improvement is through complete and careful observations, and their thorough reduction and discussion.

In the observations of double stars but little had been done before the present century, and the labours of W. Struve form the real starting-point in this branch of astronomy. These labours have been ably continued by his son, the present director of the Pulkowa Observatory, and the observations of these two astronomers, extending over a period of nearly sixty years, are of the greatest value for our knowledge of the motions of the double stars. This is a branch of the science into which irregular workers are apt to enter, and where some of them have done good service; but if any amateur astronomer will compare his own work with that of the Struves, and will study the methods followed by them in determining their personal and instrumental errors, and will emulate the steadiness with which they have followed out their purpose, he can do much to enhance the value of his labour. Here the observations are simple, and easily reduced, and the chief requisites are skill and patience on the part of the observer. He should not be discouraged because he obtains no immediate or great reward for his work, or public notice, or because some one who rants about the nebular hypothesis and kindred subjects of which he knows nothing is for a time the great astronomer of the day. The observer will learn finally that a good observation of the smallest double star, or of the faintest comet or asteroid, is worth more than all such vague talk. The observation has a positive value, however small, but the physical theories of the universe, of which modern popular science is so productive, are generally worse than useless,

The first step towards a rational and trustworthy knowledge of our sidereal universe must come from a determination of the distances of the stars. The solution of this problem was attempted soon after the Copernican theory of our solar system was established, when it was seen that we have a long hase line for our measures, or the diameter of the earth's orbit, and it was supposed that the solution would be easy. These early trials were all failures, but they led to some very interesting and important discoveries, such as Bradley's discovery of the aberration of light; to the knowledge of the fact that the determination of the parallaxes, or the distances of the stars, although simple in theory, is practically a difficult question; and then to an im. provement in the instrumental means of observation, to a careful study of the methods of observation and the instruments, and to a recognition of the necessity of a complete and rigorous reduction of the observations. An examination of these early attempts is an instructive study. It is only about forty years ago that the solution of this problem was at last attained, and then only by the application of the most powerful instruments, and the best observing skill. An interesting result of the determinations of stellar parallax is obtained at once in the check it puts on speculations concerning the structure of the sidereal universe. The first astronomers who considered the parallaxes of the stars very naturally assumed that the bright stars are nearer to us than the faint ones, and therefore they observed the bright stars for parallax. Now, while this assumption may be true as a general statement, the actual determinations of parallax show that some of the faint stars which are not visible to the naked eye are much nearer to us than the brightest stars of our northern sky. Again it was assumed that a large proper motion is a certain index of a star's nearness to us; but observation shows that this also may be an erroneous assumption. This is a problem whose solution is only just begun, but already we know enough of its difficulties to see that we need the most powerful micrometrical apparatus that can be brought into use. The invention of some micrometer that, while as accurate as the present filar micrometer, would give the observer a much greater range of observation, and enable him to select suitable stars of comparison, is something much to be desired. At present the heliometer seems to be the best instrument for observations of this kind. Formerly it was thought that photography would furnish a good method for such delicate determinations; but so far the photographic methods have not given the necessary degree of accuracy in the measurements, and the astronomical use of photography is confined mostly to descriptive astronomy, where, especially in solar eclipses, it has rendered excellent service. Closely connected with the parallaxes of the stars and their proper motions is the interesting question of determining their motions to or from our sun according to the theory of Doppler. Here -likewise the numerical determinations are so discordant, that we cannot have much confidense in the results. In both these cases we need more powerful apparatus, and a complete and thorough investigation of the methods of observation. Perhaps some of the large instruments now constructing may be employed in these methods, and we may soon have better results.

A great advance has been made in cataloguing the fainter stars. This work was begun by the French astronomers nearly a century ago, and was continued by Bessel, Argelander, and others. An important step towards the completion of this work was taken by Argelander and his assistants in their great catalogue of the approximate positions of 324,198 stars, which was finished in 186I. This census of the stars will soon be extended, we hope, over the whole heavens; and it already forms the groundwork for the great zone observations of stars now going on in Europe and in this country, and which must be nearly fini-hed. These observations will doubtless reveal many interesting cases of the proper motion of the stars, and will certainly form the basis for a knowledge of the motion of our solar system in space, and for sidereal astronomy generally, such as we have never had before. Our American observatories can render a good service by observing stars of southern declination, since our observatories are ten or twelve degrees farther south than those of Europe, and thus have an advantage of position which ought to be made use of; and which may serve to unite into a harmonious system the observations made in the northern and southern hemispheres. The work of mapping the very faint stars near the ecliptic has also been greatly extended, and it is to this extension that we owe the rapid increase in the number of the small planets between Mars and Jupiter. But besides aiding in the discovery of the asteroids, accurate charts of the small stars have a permanent value in giving us a knowledge of the heavens at their epoch, and also some idea of the distribution of the stars in space.

It is an interesting question whether, among the thousands of nebula that are scattered over the heavens, any of them show changes of form or of brightness. These objects seem to be at least as distant as the stars, and as they have sometimes an area of several degrees, they must be bodies of an enormous extent. That changes are going on in these bodies seems probable, but to be visible at such distances the changes must be very great. In this case there is need of much caution in the discussion of the drawings made at different epochs, and by different astronomers with telescopes of different power; since the nebulæ change their appearance with the telescope used, with different conditions of the air, and with a varjation of their altitude above the horizon. Here the excellent photometers that have been recently invented, and which are being so well applied to the determination of the brightness of the stars, may give us assistance. Perhaps also new drawings of the nebulx, and their criticism and discuscion, and a full recognition of the difficulties of making such drawings, will soon lead to a decision of the question of their change of form. Since the study of the light of the stars with new and improved photometers has now become a specialty, we may look for more exact and continued observations of the variable stars. This is a matter of which we know but little, and it is one where a persevering observer may do good service. Although he may not find any immediate encouragement in the discovery of remarkable relations among 
these stars, or the probable cause of their variability, he will be collecting observations that must form the test of every theory. As cxamples of the result of intelligent and persevering ouscrva. tion, we have the case of the sun-spots, which led directly to the discovery of their period, and its singular variability; and that of the shooting stars, which has shown us a very curious relation between these meteors and the corvets, and one which may open to us the most extensive views of the relations between our own solar system and other systems in space.

The present condition of astronomy, with its vast and rapidly increasing store of accurate observations, offers many interesting subjects to the theoretical astronomer. The observations of the stars are now so numerous, and have been so fully reduced and criticiserl, and the time during which the observations have been made is so extended, that we shall soon have excellent data for a new and very exact determination of the constant of precession. The orbits of the planets and the moon, and their masses, are now so well known, that little uncertainty can arise from this source; and by taking into the calculation a great number of stars in different parts of the heavens, we may be able to determine the motion of the solar system in space, as well as the constant of precession. The constant of aberration also needs a new determination, and since this constant is so closely connected with the theory of light and its velocity, and the methods of its determination are still under discussion, it would be well if several astronomers could determine this constant independently. The value we now use was found by IV. Struve from primevertical observations, and is apparently very accurate; but no astronomical constant should depend on the work of a single astronomer with a singlo instrument, when it can be determined so easily and by other methods. The old methorl of finding the value of this constant from the eclipses of Jupiter's satellites may yet give us a trustworthy value. The value of the other constant necessary for the reduction of observations, that of nutation, must be nearly that found by Peters in his well-known investigation of this question. This value may be verified by a new series of observations of Polaris, or of the declinations of stars situated so that this constant has its full influence on the reductiong.

There are many subjects in astronomy that need investigation, but in most cases the labour required is very great, and the com. pletion of the work would occupy a long time. This follows of course from the fact that, with the refinement of observations and their exact reduction, many small terms must be considered which formerly could be neglected. The lunar theory has been a vexed question for the last two centuries, and may remain so for a long time to come. This will no doubt be the case until some able astronomer, with the will and perseverance of Delaunay, shall undertake its complete revision. This question should now be looked on as a purely scientific one, and its definite solution should be undertaken. The theory should not be patched up by guesswork to fit the observations, but should be carried ont with the utmost rigour. This is a problem to which a young and able mathematician may well devotc his life, and we must expect its solution from some such clear-hearled devotec of science. Several of the planetary theories need a new investigation, and some of them are already in the hands of able astronomers. That of mercury is especially interesting in connection with the intra-Mercurial planets, and it is to be hoped that Ieverrier's theory of this plariet may soon have a careful revision.

Again, among the secondary systems, the satellites of Jupiter and Saturn offer many interesting questions to the astronomer. $\Lambda$ t present the 'satellites of Jupiter demand a more complete theory and new tables of their motions. Corrected elements of these satellites may be required for reducing observations of their eclipses, and for deriving a new value of the constant of aberration. These satellites form a peculiar and interesting system, and their theory is so complicated that the labour of correcting their elements and forming new tables would be great, but still within the power of a persevering astronomer. The recent discovery of the connection of comets with streams of meteors has given additional interest to cometary astronomy, and there is plenty of hard work to be done in reducing observations, in computing perturbations, and in deducing the best orbits of the comets. The periodical comets have another interest, since they may give us information concerning the matter filling space. It scems to be probable from different reasons, such as the consideration of the light of the stars, that there must be matter spread throughout the :celestial spaces; but the only heaventy body that has directly given us information on this subject is Encke's comet, which has a period of three years and a third. For a long time the motion of this comet was very com. pletely computed by Encke, whose calculations show very strong proof of a resisting medium. These calculations were continued by Von $\Lambda$ sten, whosc early ileath prevented him from finishing his work, and the theory of this comet is left in an unsatisfactory condition. It is very desirable that the motion of this comet should be completely investigated, and although the method of the special perturbations of the clements followed by Encke is probably the best that can be used, still in such a case it would be well to apply various methods. IIere again, on account of the frequent returns of the comet, the labour of computation is very great, and probably would be cnough fully to occupy the time of one astronomer. The interesting questions connected with the motion of this comet ought to induce some one to under. take this laborious work, and these questions are so important that two or three astronomers might well be employed on its theory.

The methods of astronomy have now become so well esta. blished that the future advancement of the science is assured, especially since long intervals of time give an increased value to observations. Yet we may hope for improvement in instruments, for the introduction of new methods of observing, for better trained and more efficient astronomers; and perhaps also the rapid advancement of the physical sciences may furnish us with new and more powerful methods of investigation. There is an intimate relation between the instrument-maker and the astronower, and they should understand each other better than is generally the casc. It may scem a small matter that the divisions of a circle, or of a scale, should not be too finely or too coarsely cut; that the reading scale should not. be placed in an inconvenient position, and that the illumination of the instrument should be carefully studied, and brought under the control of the astronomer; but these are really essential points, and, if not rightly arranged, are certain to weary thc observer and to impair the quality of his work. Such mistakes will not be remedied until the makers better understand the uses of an astronomical instrument, and have correct ideas of the end to be attained, Since our American opticians have placed themselves at the head of their craft, we may hope that our instrument-makers will do likewise, and that they will soon be able to furnish us with the best instruments of precision.

'There is one point to which astronomers should give more altention, and from which we may reasonably hope that great advantages to astronomy may come; and that is to the selection of sites for new observatories. It is possible, perhaps probable, that our instruments may be greatly enlarged and improved, and that important discoveries and improvements in the manufacture of optical glass may be made; but it scems certain that we have within easy reach very decided advantages for astronomical work by the choice of better positions for our instruments. Very few $\Lambda$ merican obscrvatories have been established for the purpose of doing scientific work, or with much thought or care for their future condition; but generally they are built in connection with some college or academy, and are the product of local and temporary enthusiasm, which builds an observatory, equips it with instruments, and then leaves it helpless. The atmosphere that sur. rounds $u \varepsilon$, and its sudden changes of temperature, are the great obstacles to the good performance of a telescope; and the larger the instrument, and the higher the magnifying power, the more serious are these hindrances. Now, with our present means of travel, we can easily place our instruments at an altitude of eight or ten thousand feet, and above a large part of the atmosphere. In this way we may be able to do with small instruments what at common altitudes can be done only with large ones; and when possible it is always better to use small instruments, since they are more easily handled, and are relatively stronger and better than large ones. Uniformity of temperature may be secured loy seeking locations in the tropical islands, or on coasts likc that of California, where the ocean winds kcep the temperature nearly uniform throughont the year. At great altitudes we may secure a clearness of vision that would be of the greatest value in the examination of faint objects, and by this means, and by persevering and continuous observation, interesting discoveries may be madc. It is a matter of course that, except in the case of comets, the future discoveries in astronomy will belong to faint and delicate objects; but these are interesting, and should not be neglected. A uniform temperature, which secures good definition, and steady images of the stars, is necessary for accurate determinations of position, and for all measurements of pre 
cision. This condition is especially important in such work as that of stellar parallax, the determination of the constant of aberration, and wherever the yearly change of temperature may act injuriously. In the selection of better sites for observatories I think we have an easy means of advancing astronomy.

As this science grows and expands, it will become more and more necessary to study the economy of its work, in order that astronomers may bestow their labours in the most advantageous methods, and may rid themselves of all cumbersome and time. consuming processes. The manner of publishing observations has already been much abbreviated, and improved I think, by some of the European astronomers, and this change seems destined to become universal. As the positions of many objects are now well known, the need of printing all the details of the observation, such as the transits of the wires, the readings of the micrometers, \&c., is very slight; and this printing may be safely abandoned. Even this change will lead to a great saving in the time and cost of printing. But this will necessitate a more complete discussion of the work, and a more careful examination of the instruments; things to be desired, since they tend to lift the observer out of his routine, and make him a master of his business. There are objections to this change, and some of them are real, such as the importance of publishing a complete record; but this is overestimated, I think, since the original records ought always to be referred to in case of doubt; and other objections are factitious, such as the need of publishing a large and showy book in order to impose on the public.

We may hope also for improvements in theoretical astronomy, and for the better training and preparation of students of this science. I know that it is sometimes said that theoretical astronomy is finished, and that nothing more can be done. Such assertions come from professors who are old and weary, or from those young men who tire out early in life ; but they are wrong. The improvements that Hansen has made in the theory of perturbations, and Poinsot's study of the theory of rotation, show what careful investigation may do, and assure us of further progress. It must be confessed that some of the astronomical work done in our country bears evidence that the astronomers did not understand the correct methods of reduction, and much of it shows evidence of hasty and ill-considered plans. This is perhaps a natural condition for beginners, but we trust that it has been outgrown. An actual need for the astronomical students of our country is a good book on theoretical astronomy, similar to Pontécoulant's work, in which the whole subject shall be presented in a complete form, such as we find in the "Mécanique Céleste," together with an account of the improvements made by Gauss, Poisson, Hansen, and others. There is no American book of this kind, and the English works are too partial, designed apparently to fit the student for college examinations, and not to give him a complete knowledge of the science. Such a book has hardly been attempted in our language, unless that of Woodhouse may be an exception, and it may be a long time in coming, since it requires a man qualified to do the work, and will involve an expense of labour in the preparation and of cost in publishing such as few are willing to incur. In the mean time it is far better for the student to go directly to the writings of Lagrange and Laplace, of Gauss and Poisson and other masters, rather than to spend time in reading second-rate authors who endeavour to explain them. And generally this will be found the easier way also, since the student avoids the confused notions and symbols, and the grotesque expressions and egotism of small men, and is lifted into the region of ideas and invention.

In presenting his exposition of the nebular hypothesis, which has since become so celebrated, Laplace says: "I present this hypothesis with the distrust which everything ought to inspire that is not a result of observation or of calculation." It is a singular fact that, among all the writings on the nebular hypothesis, I have never seen a reference to this presentation of it by its most distinguished advocate; and yet this is the true spirit of scientific astronomy. Laplace did not wish to exempt his own theories frum criticism, and neither should any one. In astronomy there is no final human authority, no synod or council, but simply an appeal to reason and observation. If a theory or a discovery be true, it will stand the test of observation and of calculation; if false, it must pass away to that Miltonian limbo where so many things have gone and are going. The question is sometimes asked, Of what use is astronomy? and the reply generally made is that it has conferred great benefits on navigation and on commerce, since it is by means of his astronomical knowledge that the sailor determines the position of his ship on the ocean. There is a truth in this reply, but it is only partial. The great value of astronomy is that it is really a science and that it has broken the path and led the way through which all branches of science must pass if they ever become scientific. It is the spirit of honest, unrelenting criticism, and of impartial examination, that finally eliminates error and awards to every one his just due, that makes astronomy honourable and attractive ; and it is by cultivating this spirit that astronomy confers its chief benefit, for it is this that shall break in pieces and destroy all false assumptions in science and in philosophy.

\section{SCIENCE IN NORWAY}

$W^{E}$ have received several publications from Norway of scientific interest.

Nyt Magazin for Naturvidenskaberne. B. 25, H. 4.

\section{(Kristiania, 1880.)}

In this number of the Norwegian "New Magazine for Natural Sciences" Herr Hansen continues his description of the annelids yielded by the Norwegian North Sea Expedition of $x 878$, to which he appends drawings of his own of all the rarer forms.-Herr L. Schmelck gives the results of bis analysis of sea-water obtained in the same voyage within and near the Polar circle. The water was taken at various depths, and was obtained from a stratum intermediate between the surface and the bottom by means of an apparatus devised for the purpose by Herr Tornöe.-Herr Brögger and Reusch's observations on the character and localities of Norwegian apatite, which originally appeared in 1875 in the Zeitschrift d. deutschen geologischen Gesellschaft, are here translated into Norwegian by the authors, who have made various additions to their paper, which is illustrated with numerous drawings. - In a paper on the Lepidoptera of Norway by W. M. Schöyen the author draws attention to the number of new forms added to this branch of the Norwegian fauna since the publication, in 1876 , of Siebke's list of the insects of Norway. The number given at that time for the lepidoptera was 934 ; it is now raised to 1 ,org. The writer's own contribution to these is 38 hitherto undetected Norwegian species, the habitats and characters of which he describes.

Kort Fremstilling af de Norske Kursteders Udvikling, \&c. Ved Axel Lund, M.D. (Kristiania, 1880.)--In this brochure we are reminded that Norway, from her geognostic character, is naturally deficient in thermic springs, and we are shown that till recently the water-cure-taking the words in a comprehensive sense to include the use of waters internally and externally-was unknown in the country. In fact even now the Norwegians stand exceptionally low in the scale of water-using nations, although an encouraging change in this respect has been manifested of late years by the establishment of mineral and sea-bathing places in various parts of the kingdom. These Dr. Lund describes at great length, giving the analysis of the waters yielded by the few springs that have been opened, and the amount of salt present in the sea-water at the various marine stations, with the medical reports of each and the mode of treatment adopted. In the last respect the only difference that we observe from the system generally followed at German baths is that at the seabathing establishment in the Sandefjord, a small species of Medusa is used to excite local irritation in cases of cerebrospinal, rheumatic, or neuralgic affections, by passing the animals rapidly over the $\mathrm{p}^{\text {nrts }}$ affected. To Dr. Thaulow, the founder of the baths at the Sandefjord and at Modum, the Norwegians owe a large debt of gratitude as the first of their countrymen who drew public attention to the paramount importance of baths as a hygienic agent. Sweden has long been in advance of Norway in its appreciative comprehension of the curative value of mineral and sea waters; and from Dr. Lund the reader will learn all that there is to learn in regard to the water-establishments, springs, and baths of the sister kingdom, while he may also gather some information respecting similar institutions in the Danish dominions. In conclusion, we may observe that some of the newly-opened Norweglan water-cure establishments, as that of Modum, lying in the midst of pine-woods, and the sea-bathing places on the Sandefjord and Kristianiafjord, offer numerous attractions to foreigners in respect to salubrity of air, beauty of position, and moderate cost of living.

Knudshö, eller Fjeldforaen. J. B. Barth. (Kristiania, 1880.) - Herr Barth, who is well known for his animated descriptions of the natural scenery of his country, and his lively narrative of 